\title{
Impact de la Bruyère arborescente (Erica arborea) sur l'activité ruminale de chèvres valorisant des zones embroussaillées en Roussillon
}

\author{
JP Goby, JJ Rochon
}

I.U.T., Chemin de la Passio Vella, 66860 Perpignan Cedex, France

Les troupeaux caprins laitiers utilisateurs de zones marginales en région méditerranéenne française ont un double objectif : production laitière et contrôle de l'embroussaillement dans des zones sensibles aux incendies (Goby et al, 1994, Cah Opt Med, 5, 69-82). Des mesures de comportement ont montré qu'une proportion élevée de Erica arborea était prélevée par les animaux, ce qui est peu compatible avec la composition chimique de cet arbuste (Goby et al, 1994, Ann Zootech, 43, 294).

Afin de mieux comprendre le rôle digestif de Erica arborea dans le rumen, des mesures de digestibilité ont été effectuées sur 3 chèvres fistulées, nourries avec 2 régimes : 1 régime $100 \%$ foin ( $F O$ ) et 1 régime foin + bruyère (FO + BA). Chaque série de mesures a été complétée par un suivi de la cinétique de 3 paramètres ruminaux $\left(\mathrm{pH}, \mathrm{NH}_{3}, A G V\right)$ et une mesure de dégradabilité $48 \mathrm{~h}$ de la matière sèche (D48h) de Erica arborea (BA), du foin (FO) et de la paille ammoniaquée (PA) utilisée comme témoin. Pour le régime $\mathrm{FO}+\mathrm{BA}$, l'apport du foin s'est fait par moitié le matin jusqu'à $12 \mathrm{~h}$ et par moitié le soir à partir de $18 \mathrm{~h}$, la bruyère étant distribuée de $12 \mathrm{~h}$ à 18 $h$. Ce rythme d'alimentation correspond à celui pratiqué par les éleveurs. Pour tenir compte des capacités de choix de la chèvre, la bruyère récoltée chaque jour a été distribuée sous forme de fagot de $500 \mathrm{~g}$ (poids frais). Toutes les heures, les refus ont été pesés et la bruyère arborescente renouvelée. La connaissance des prélèvements effectués par la chèvre sur cet arbuste (Méthode des coups de dents) nous a permis d'évaluer le poids de matière sèche ingérée.

Pour la bruyère, la $\mathrm{D} 48 \mathrm{~h}$ ruminale est identique dans les deux régimes. Sa teneur élevée en lignine (30\%) limite l'attaque des bactéries sur les fibres. Le régime $\mathrm{FO}+\mathrm{BA}$ a une influence positive hautement significative sur la D48h de la paille ammoniaquée et du foin. Ce résultat, couplé à l'évolution significativement différente des 3 paramètres ruminaux à $14 \mathrm{~h}$ dans les 2 régimes, permet de penser que la bruyère, dès son ingestion, va activer l'action cellulolytique des bactéries sur les fibres issues du foin présent dans le rumen.

Les résultats identiques de quantité ingérée et de digestibilité totale des 2 régimes ne sont donc pas dus à une même utilisation digestive des 2 constituants mais à une meilleure valorisation du foin lors de l'introduction de bruyère arborescente dans le régime.

Cet arbuste de faible valeur nutritive possède la capacité de stimuler rapidement la flore ruminale et d'activer la dégradation des fibres des fourrages présentes dans le rumen.

Paramètres ruminaux

\begin{tabular}{|c|c|c|c|c|c|c|c|c|c|}
\hline \multirow[b]{2}{*}{ Régime } & \multicolumn{3}{|c|}{ D48h (\% MS) } & \multicolumn{2}{|c|}{ Quantité ingérée } & \multirow{2}{*}{$\begin{array}{c}\text { Digestibilité } \\
\text { (\% MS) }\end{array}$} & \multirow[t]{2}{*}{$\mathrm{pH}, 14 \mathrm{~h}$} & \multirow{2}{*}{$\begin{array}{c}\mathrm{NH}_{3}, 14 \mathrm{~h} \\
(\mathrm{mg} / \mathrm{l})\end{array}$} & \multirow{2}{*}{$\begin{array}{c}A G V, 14 h \\
(\mathrm{mM} / \mathrm{l})\end{array}$} \\
\hline & $\mathrm{BA}$ & $\mathrm{FO}$ & $\overline{P A}$ & FO & BA & & & & \\
\hline$=0$ & $39,7^{a}$ & $51,0^{a}$ & $64,7^{a}$ & & & $52,8^{a}$ & 6 , & $\mathrm{aa}$ & $8^{a}$ \\
\hline & & & \pm 5 & $1680 \mathrm{~g}$ & & & & & \\
\hline $\mathrm{FO}+\mathrm{BA}$ & $41,6^{a}$ & 57 & $73,3^{b}$ & & & $51,4^{a}$ & 5 , & 25 & $53^{b}$ \\
\hline & $\pm 1,8$ & $\pm 0,9$ & $\pm 3,2$ & $837 \mathrm{~g}$ & $835 \mathrm{~g}$ & & $\pm 0,07$ & $\pm 0,10$ & $\pm 5,88$ \\
\hline
\end{tabular}

